\title{
INTERVIEWS
}

Professor Ignacio Tirado, Secretary-General UNIDROIT*, talks to Alicja Jagielska-Burduk ${ }^{* *}$,

Claudia S. Quiñones Vilä́t*, and Paul Fabel ${ }^{\star * * \star}$

\section{The Role of UNIDROIT in Global Efforts to Protect Cultural Heritage}

Alicja Jagielska-Burduk (AJB), Claudia S. Quiñones Vilá (CQ): As Secretary-General of UNIDROIT, you are constantly in communication and engagement with individuals and organizations with a global reach. What is your perspective regarding the role of cultural heritage as a bridge between societies and its potential to initiate constructive dialogues and policy development?

Ignacio Tirado: Cultural heritage is paramount to substantiate solid and sound international relations between States. Cultural heritage is the soul of a country, how it stands in the world, how it has evolved over history. It is what makes each country unique and special, and hence it is the basis for internationalism. We travel abroad and we study the history and traditions of different places precisely because they are different and special: if all countries were equal, why travel? Why take an interest in a neighbour, or in a beautiful far-away land? When UNIDROIT protects and preserves cultural property, it is creating enormous value for the international community. This is why we are so proud of our work in the field.

\footnotetext{
* Professor Ignacio Tirado, Secretary-General UNIDROIT.

** Alicja Jagielska-Burduk serves as Editor-in-Chief of the "Santander Art and Culture Law Review" (orcid.org/0000-0001-6696-8004).

*** Claudia S. Quiñones Vilá is a lawyer at Amineddoleh\&Associates LLC, New York City, USA (orcid.org/0000-0001-9238-6227).

**** Paul Fabel is a Fellow on Cultural Heritage Protection within the Mercator Fellowship for International Affairs (orcid.org/0000-0002-8729-3779).
} 


\section{INTERVIEWS}

Professor Ignacio Tirado, Secretary-General UNIDROIT, talks to Alicja Jagielska-Burduk, Claudia S. Quiñones Vilá, and Paul Fabel

But not just any work will do - we have to be efficient and effective. I cannot overstate the importance of joint and coordinated actions to strengthen the safeguarding of cultural heritage: intergovernmental institutions need to work together and we, IGOs, need to move forward hand in hand with countries, as well as with the private sector. The relevance of the private sector, of industry, is paramount. The Convention tries to prevent illegal and illegitimate dealings, and it is hence to some extent acting as a regulatory force in the art market. Market parties need to collaborate and cooperate if a clean, adequate, and well-functioning market is to thrive.

Naturally, the success of the Convention, and generally of our work in the field, depends on how well the regulatory framework is able to integrate private and public law rules. Achieving this aim, this balance, is both a challenge and an opportunity for us and for our partner organizations. But in order to achieve success we need more than just sufficient institutional collaboration and an adequate set of norms - we need to get to the roots of the problems and educate people how to protect cultural property and combat illicit trafficking. We devote an important part of our budget to this topic in the context of training and capacity building. And it is never enough.

But coming back to the institutional relationships, the 1995 UNIDROIT Convention goes to the heart of the UN Sustainable Development Goals: in view of the globalization of the illicit trade in cultural objects, it is crucial that all countries adhere to international conventions in this field in order to prevent their own heritage and that of humanity from being further impoverished. In particular, our Convention is concerned with Goal 4 (Quality education), 11 (Sustainable cities and communities), and 16 (Peace, justice and strong institutions - in particular 16.4 "by 2030 significantly reduce illicit financial and arms flows, strengthen recovery and return of stolen assets, and combat all forms of organized crime").

\section{AJB and CQ: How are cultural property legal issues situated within UNIDROIT's areas of involvement, particularly among other relevant and definitively business sector-oriented ones such as works regarding agricultural land investment or the MAC Protocol?}

I think some of the ideas included in the answer to your previous question would address this question too. On a slightly tangential note, it might be worth mentioning that the 1995 Convention not only effectively tackles abuses committed in international trade of cultural goods, but also contributes to legal certainty in the circulation and trade of cultural goods at the global level. In a way, our instrument is the main international instrument out there which directly deals with the market 
(i.e., private law) side of cultural property; it is the part of the equation that would otherwise be missing from the regulation of an international trade of cultural objects which would act only in the sphere of public law. Our instrument helps drain the market of objects that should not have a market. It is, in a way, also business-oriented since it protects the market and ensures protection for those who conduct trade in a legitimate manner. I see a full consistency among all our instruments.

\begin{abstract}
AJB: At the 77th session of the General Assembly of UNIDROIT, which took place on 6 December 2018, you mentioned that you have plans to develop more scientific initiatives for scholars visiting UNIDROIT's library. Last year, the UNIDROIT 1995 Convention Academic Project (UCAP) - which we described in the "SAACLR" 2017 2(3) issue - was launched. Given your scientific background and experience in conducting research, what are your thoughts about this Project and how are you going to support it as Secretary-General?
\end{abstract}

The UCAP is mainly aimed at achieving good knowledge and a deep understanding of the UNIDROIT 1995 Convention and other related instruments among students, scholars, universities, and professionals working in the art field. But this is not all; we are more ambitious, and, in the mid-term, we would like to become an influential think-tank on cultural heritage law matters. At least as regards the private law side of cultural heritage, we are second to no other institution.

In more precise terms, as an "academic" Secretary-General, I intend to substantially strengthen our research side, creating - once again - a hub for intellectual and academic debate and exchange. A very good example of this is our work towards more and better collaboration with high-level universities and research centres, through the conclusion of MoUs and stable collaboration agreements. Naturally, we seek to bolster our academic ties concerning all our areas of work, including also those institutions and projects who want to be linked with the UCAP (Opole or Nicosia for example). We certainly welcome professors and students wishing to spend a period at UNIDROIT for research, and we want them to share their research with us. We want to both give and receive; to be enlightened by specialists in the field, and to provide our own view of the law, based on our expertise. This is a win-win exchange.

Finally, I cannot fail to mention that UCAP also aims at feeding the discussions of the Informal Ratification Task Force - created in New York in 2017 - which should meet once a year under the auspices of the Secretary-General of UNIDROIT. 


\section{INTERVIEWS}

Professor Ignacio Tirado, Secretary-General UNIDROIT, talks to Alicja Jagielska-Burduk, Claudia S. Quiñones Vilá, and Paul Fabel

AJB: As a representative of the University of Opole, I would like to express my sincere gratitude that the Memorandum of Understanding has been signed between our institutions. The newly established UNESCO Chair on Cultural Property Law at the University of Opole is obviously one of the potential areas of cooperation. So far we have been cooperating within the UCAP. I strongly believe that the MoU will broaden our future cooperation. What is your strategy on cooperation with higher education sector; do you have any particular plans?

Our goal is to strengthen cooperation between UNIDROIT and academia. We are working on broadening our network of universities worldwide to include some of the most important universities and research centres. I am convinced that UNIDROIT is the right institution to link academic work of excellence and international legal reform. Moreover, it can act as a conduit between standard setting and domestic legislations, a step which is best taken together with academic experts at national level. Two good examples of our activities in the field are the UCAP, which brings together organizations and individuals working on cultural property law, and the Cape Town Convention Academic Project, where we partner up with Cambridge University and the private sector to provide awareness and high-level legal analysis in the area of secured transactions.

CQ: Pursuant to Decision (EU) 2017/864 of the European Parliament and of the Council of 17 May 2017 on a European Year of Cultural Heritage (2018) and the European Commission Proposal for a Decision of the European Parliament and of the Council on a European Year of Cultural Heritage, COM (2016) 543, 2018 was declared as The European Year of Cultural Heritage (EYCH). The primary aim of EYCH is to encourage more people to discover and engage with Europe's cultural heritage, and to reinforce a sense of belonging to a common European space. What are your thoughts on this initiative? Do you believe there is such a thing as a European culture? If so, why is it important?

On a personal note, as a European I have absolutely no doubt that there is a European culture. After so many years travelling around the world in my work, getting to know very disparate and unique cultures, I have understood that - despite what many Europeans may think - the difference between European cultures is one of mere detail. I guess this is only evident when you have lived and submerged yourself in far-away cultures, because it gives you a perspective that you may not otherwise have (as you are "too close to the leaves to see the forest"), but it is nevertheless something I am profoundly convinced of.

I am not saying there are no differences; only that the common, shared ground is stronger, and unique. Differences within Europe are beautiful and they must be 
recognized and respected (see the Maastricht Treaty: "The Community shall contribute to the flowering of the cultures of the Member States, while respecting their national and regional diversity"). However it is also important for European citizens to feel that beyond such diversity there is an entity (the EU now) which protects what becomes a "common" cultural heritage. Through this mission, the EU is engaged in an extraordinarily important task.

However, as a Secretary-General I would like to highlight that although Europe and European States are a very important part of our constituency, we are a global institution, and that we respect, support, and strive to preserve all cultures around the world.

Concerning your reference, UNIDROIT is a member of the Stakeholders Committee of the $2018 \mathrm{EYCH}$. To ensure that the EYCH leaves a political footprint beyond 2018, the European Commission, in collaboration with key partners, is carrying out long-term projects (called the 10 European initiatives) which correspond to the four principles that define the EYCH: Engagement, Sustainability, Protection, and Innovation. Under Initiative 7 - "Heritage at risk: Fighting against illicit trade in cultural goods and managing risks in heritage sites" (Protection Pillar) - UNIDROIT is collaborating with (1) UNESCO on Component 2 ("awareness raising and capacity building activities"), with the art market and law enforcement entities and the judiciary; as well as (2) with research teams working at a better understanding of illicit trade in cultural goods on Component 3 ("improving evidence and sharing experience") with a view to the publication of an EU study.

AJB: The concept of due diligence provided in the 1995 UNIDROIT Convention is
a standard-setting model, yet the impact of UNIDROIT's legal developments goes far
beyond the Convention's scope. This is visible in Directive 2014/60/EU of the Europe-
an Parliament and of the Council of 15 May 2014 on the return of cultural objects un-
lawfully removed from the territory of a Member State and when it comes to the 1970
UNESCO Convention's provisions. Therefore, there is a strong need to create networks
such as the Task Force announced during the event on "Promoting and strengthening
the international legal framework for the protection of cultural heritage" (28 Feb-
ruary 2017), at the UN HQ. What is your opinion of building networks in this field? International cooperation is indeed a key element and a way to achieve it is by building networks and partnerships at all levels - institutional, academic, professional, etc. UNIDROIT is involved in several networks and partnerships; to name only a few we work hand in hand with INTERPOL (member of its Expert Group on Stolen Objects), UNODC, WCO (with ARCHEO network), ICOM (International Observatory on Illicit Traffic), and with ICCROM. 


\title{
INTERVIEWS
}

Professor Ignacio Tirado, Secretary-General UNIDROIT, talks to Alicja Jagielska-Burduk, Claudia S. Quiñones Vilá, and Paul Fabel

At the Ratification Task Force meeting at the UN in New York, there was wide acknowledgment of the importance of a holistic, multidisciplinary approach to addressing the matter and of the need for complementarity and synergies between the crucial work of international organizations and the numerous important international legal instruments.

\begin{abstract}
AJB and CQ: The topic "Private art collections" was included in the UNIDROIT Work Programme for the 2017-2019 triennium. The General Assembly endorsed the recommendation made by the Governing Council on this matter at its 75th session (Rome, 1 December 2016) and assigned it a low level of priority. In our opinion, private collections as well as private actors' engagement are at the core of the future cultural heritage protection model. Only by involving private actors in equal dialogue in the cultural property debate can it lead to success, and UNIDROIT has a very important role in enhancing and encouraging this cooperation. In your opinion, what challenges does this topic face nowadays? What do you believe is the role of private parties, specifically collectors, in cultural heritage management in light of these terms?
\end{abstract}

The complementarity of the 1995 UNIDROIT Convention with the 1970 UNESCO Convention is based precisely on our providing rules concerning the private law aspects of the problem. As is well known, the 1995 UNIDROIT Convention allows private actors to protect cultural heritage by claiming the property stolen or illegally trafficked from them. Our instrument gives them the key: it is up to them to use it.

As to private collections, they play an important role, for example in alleviating the difficulties of public museums by lending or donating works of art. It is therefore important to give a status to such collections and examine issues such as, for example, the following (and this is to be read merely as a list by way of example): the right of disposal of artworks in possession of an art collector under a certain municipal law; the liability of art collectors for loss, damages, or destruction of cultural property forming part of their collections; the sale of part or the entire content of an art collection; the limits of the protection of art collections in case of suits/ arrests, and immunity from seizure status; or provenance investigations at the time of the acquisition of cultural items. But private collections may also be a way to conceal objects and "wash" provenance. UNIDROIT works at raising awareness of collectors as to the ethics in acquisition (trainings with UNESCO) (concept of due diligence when acquiring, Article 4(4) of the 1995 UNIDROIT Convention; Article 4(5) on caution as to donations). 
Paul Fable (PF): With the aim of complementing the EU legal framework combating the illicit trafficking of cultural property, the EU Commission proposed a regulation in summer 2017 restricting the import of cultural goods into the single market of the 28 EU Member States. This proposal has been criticized for not fully complying with international law standards. What is UNIDROIT's position on the proposed text and what should this legal instrument look like in order to have a more harmonized text?

In a way, it seems perhaps now too late to criticize a text which was adopted by the European Parliament in March 2019. Criticism would bring no benefit and only serve the purpose of undermining what can constitute an important piece of legislation. UNIDROIT, together with UNESCO, were consulted during the elaboration of the Regulation on import and made joint comments both to the Commission and the European Parliament in view of the synergy with our instruments, highlighting several points in the draft Regulation in order to facilitate its consistency with international law. UNIDROIT and its partners also stressed the necessity to have an instrument which would be "practically implementable". In any case, we stand ready to help the EU in its efforts to protect cultural heritage.

PF: During the last four years, illicit trafficking of cultural property has increasingly been linked to terrorism financing, be it through reports in the media, security reports from some Member States, or international organizations. Even the UN Security Council has adopted resolutions on that topic in the period 2015-2017. However, critics say that terrorism financing cannot be proven by simply referring to an archaeological object from a region in conflict; for example, lacking a direct link to the object, its proceeds and the possible terrorist activity is not possible to prove. What is your view on this situation, and what are your suggestions for institutions such as UNIDROIT which are active in this field: Should they adapt their wording in order to avoid receiving criticism?

The links between illicit trafficking in cultural property and the financing of terrorism are expressly recognized by the UN Security Council in Resolution 2199 (2015), in particular in its Paragraph 16 where it notes with concern that the EIIL, the El Nosra Front, and other individuals, groups, businesses, and entities associated with Al-Qaeda generate revenue through the looting and smuggling, directly or indirectly, of cultural goods from archaeological sites, museums, libraries, archives, and other sites in Syria and Iraq, which are then used to fund their recruitment efforts or to improve their operational capacity to organize and conduct terrorist attacks. Some information is available from the Monitoring Team on the quasi-bureaucratic modalities of the illicit trade organized by these entities. This must 


\section{INTERVIEWS}

Professor Ignacio Tirado, Secretary-General UNIDROIT, talks to Alicja Jagielska-Burduk, Claudia S. Quiñones Vilá, and Paul Fabel

be sufficient to act and for States to take measures (an obligation under Chapter 7 of the UN Charter!).

Furthermore, according to the Foundation for Defense of Democracies (http://www.defenddemocracy.org), the funding that the Islamic State draws from the trade in cultural goods is "increasingly important today, considering that access to other sources of funding is becoming increasingly difficult" (report Monumental Fight: Countering the Islamic State's Antiquities Trafficking, 2015).

"Adapt the wording to avoid criticism"? Even if such activity would give only US $\$ 1$ to criminals, it would be too much and justify action. Avoiding criticism is impossible as too many diverging interests are at stake, and yet dialogue is essential.

\section{PF: In times when international cooperation is being challenged by the withdrawal of funds from international organizations by some governments, how do you view the future of multilateralism? More precisely, what do you think is the added value of international organizations like UNIDROIT, and what is it that you can bring to the table in terms of international cooperation?}

This a crucial, yet difficult question to answer. In a way, multilateralism has always been under attack; and yet it has always managed to survive. Multilateralism is the natural place for States to meet, for countries to engage in exchanges; it is the world's common backyard. It simply cannot disappear. This is even more clear nowadays, with the deep integration of regional and international markets, which is, we should not forget, the realm of private law and hence the realm of UNIDROIT. Markets and exchanges between countries are too intertwined, too intermingled. If you allow me to borrow a famous expression - "you can't unscramble scrambled eggs".

These are days when financial constraints are a fact; while at the same time there are widespread voices to close borders and to concentrate on one's own matters; but these are not enough to inflict self-harm on the citizens of the countries more prone to such practices nowadays. There is still plenty of space for multilateralism. And, as always, it will survive and thrive. The place of UNIDROIT, like that of our sister organizations, is to aid in creating a level-playing field for countries to maximize their exchanges, to reach a consensus. Doing away with that is unthinkable. 